\title{
A STUDY OF ASSOCIATION BETWEEN MATERNAL PLACENTAL WEIGHT AND NEONATAL CHARACTERISTICS
}

Jayun. M. Joshi, Dimpal Patel

1. Assistant Professor, Department of Obstetrics \& Gynaecology, AMC MET Medical College, Ahmedabad

2. Associate Professor, Department of Obstetrics \& Gynaecology, AMC MET Medical College, Ahmedabad

\section{CORRESPONDING AUTHOR}

Dr. Jayun M. Joshi,

24, Jagatjanani Society, behind Polytechnic,

Ambawadi, Ahmedabad 380015.

E-mail: drjmjoshi@gmail.com,

Ph: $009109427711313,00919974011495$.

ABSTRACT:BACKGROUND: Placenta is a vital organ in normal fetal development . Failure of placenta to gain weight and insufficiency of its function can result in fetal disorders. This study is to determine placental weight and factors associated with low weight placentas. STUDY DESIGN: This is the a longitudinal cross-sectional study in which women with single pregnancy, and gestational age between 37-42 weeks were studied. The subjects were categorized in high (> $750 \mathrm{~g})$, normal (330-750 g), and low placental weights $(<330 \mathrm{~g})$. The placental weight, maternal age ,birth weight, , parity, gestational age, preeclampsia, history of maternal diabetes, delivery routs, neonates' gender; and apgar score in $5^{\text {th }}$ minutes after delivery were examined. One thousand-eighty eight pregnant women were included in the study. RESULTS: The mean and standard deviation for maternal ages and gestational ages at deliveries were $25.35 \pm 5.6$ and $274.51 \pm 9.56$ days, respectively. The mean and standard deviation of neonates' weights at birth and placental weights were $3214.28 \pm 529$ and $529.72 \pm 113 \mathrm{~g}$, respectively. The prevalences of low and high placental weights were $2 \%$ and $2.8 \%$, respectively. There were statistically significant relationships between placental weight and birth weight, fetal distress, Apgar score, maternal diabetes, preeclampsia and routs of deliveries $(\alpha=0.05)$. CONCLUSION: Findings indicate that placental weight can be associated with important variables influencing some maternal and neonatal outcomes and placental weight lower than $330 \mathrm{~g}$ can be a warning sign. Careful attention to placenta growth during pregnancy can guide physicians to assess neonatal health.

KEY WORDS : Placenta, pregnancy, delivery ,birth weight

INTRODUCTION: Placenta is the most important organ for maintaining healthy pregnancy. It exchanges gases and nutrients needed for fetus. The examination of placenta would demonstrate important information about whatever has happened on fetus. As fetus grows, many changes happen in placental shape and function that reflects changes in needs of fetus in different growth stages. To achieve this, metabolic, immunologic and endocrine changes should happen in placental trophoblast. Placental weight reflects placental development and functions and is correlated with maternal age, gestational age, history of maternal diabetes, preeclampsia, birth weight, parity, route of delivery, infants' gender and Apgar score and fetal distress. Other factors influencing placental weight include parity, maternal height and weight (1). Increase in placental size is significantly associated with maternal weight, and it is an independent predictor of birth weight. Large placental size and low birth weight have been implicated as factors predicting high blood pressure in adulthood (1). It has been shown that maternal or fetal 
diseases (gestational diabetes, severe anemia, hypertension and hydrops fetalis) influence fetal and placental weight (2-5). Barker et al. showed the higher blood pressures have occurred in later life who had been small babies with large placentas (6). It has been shown that placental weight has a significant role in fetal growth in terms of weight, body length, and cord length but it has no significant role in the presence of meconium-stained fluid (7). While some other studies have shown less correlation between mentioned factors and placental weights, Little et al. showed that absolute measures of infant size and placental weight had mutual positive correlation (8). We had evaluated the prevalence of low placental weight; and determine the impact of placental weight on infants' characteristics. The results of this study would have an important implication for obstetrics decisions.

MATERIALS AND METHODS: We examined all pregnant women referred to our hospital. Inclusion criteria were as follows: women with singleton pregnancy, and known gestational age $\geq 37$ weeks. Exclusion criteria were as follows: women with unknown gestational age, intrauterine growth retardation (IUGR), and twins. In a pilot study after placentas expulsion, every placenta was dried, then its membrane was cut and the placental weight measured. In addition, infants were weighted. We found mean and standard deviation (mean \pm 2 SD) as normal values $537 \pm 105 \mathrm{~g}$ (328-744 g). Accordingly, the women were categorized as high placental weight (> 750 g), normal placental weight (330-750 g) and low placental weight (< $330 \mathrm{~g}$ ) groups. We used Statistical Package for Social Sciences (SPSS) for windows, version 9 for statistical analysis.

RESULTS: 1088 pregnant women were included in this study. Findings are represented in Tables 1, 2, and 3. There were no significant difference between placenta weight and neonates genders; as well as between placenta weight and gestational ages $(\mathrm{P}=0.34)$. Also, there was no significant difference between placenta weight and presence of major anomalies. There were more low-weight placentas in under 19 years and more high-weight placentas in 30-34 years age groups. There were more low-weight placentas in preeclamptic mothers $(8.1 \%$ vs. $1.6 \%)$ and more ( $20 \%$ vs. $2.6 \%$ ) high-weight placentas in diabetic mothers. More (17.4\% vs. $0.8 \%$ ) low weight placentas were found in under 2500 grams neonates while no low-weight placenta was found in over 3500 grams neonates weight group. There were lower Apgar scores in neonates with low-weight placenta and more fetal distresses and more Caesarean section in placentas with abnormal weight.

DISCUSSION: Placental hypertrophy and reduced fetal growth have been postulated to be an adaptation to maintain placental function in pregnant women with conditions such as malnutrition. As such, the pregnancy with impaired fetal growth, resulting in small for gestational age (SGA) neonates, should have an increased placental weight to birth weight ratio (placental ratio) compared to those with appropriate for gestational age (AGA) or large for gestational age (LGA) infants; but studies have shown that this is not true (9). Heinonen et al. showed that placental actual weight was lower in SGA infants than in AGA infants with the same birth weight (2). It seems that low birth weight should be related to low functional tissue mass of placenta; and this is accompanied by diminution of the area for exchange between mother and fetus, both at the villi and at fetal capillary surface area. Thus, the ability of exchanging oxygen and nutrition from mother to fetus is curtailed. 
Our findings showed that the prevalence of low weight placenta in SGA infants was 17.4\%; but this is not true in infants with weight more than $3500 \mathrm{~g}(\mathrm{P}<0.0001)$. Furthermore, fetal growth capacity is determined by placental weight (7). The placental ratio tended to increase from the LGA group to the SGA group both for women with uncomplicated pregnancies and with pregnancies complicated by intrauterine growth retardation or for women with pregnancy induced hypertensions (3). Perry et al. showed there was no significant difference between the mean placental weight and preeclampsia and gestational hypertension (4).

The pathophysiology of hypertension in pregnancy is unknown, and current therapies for preeclampsia aimed preventing the maternal syndrome, not preventing the primary pathophysiology but genetic and environment factors may caused this complication (10). Bortolus et al. have shown that pregnancies with induced hypertension result high weight placentas (11). Our findings indicate that not only the prevalence of high placental weight is higher in preeclampsia but low placental weight prevalence also in preeclampsia is higher than uncomplicated pregnancies. As if, the mean placental weight showed a significant increase from the SGA to the LGA. Our results were similar to this research.

One of the principal reasons for this problem in our study is because of the more nulliparous women; and nulliparity is a risk factor for high prevalence of this disease. Preeclampsia incidence according to our results and Perry's study on the healthy nulliparous pregnant women was $6.8 \%$ and $7.3 \%$, respectively (4).

We found the prevalence of gestational diabetes mellitus (GDM) $0.9 \%$; much lower than other studies; perhaps because we had more younger subjects than other investigators (with $75 \%<29$ years), as GDM is more common after 30 years old (12); also perhaps because insufficient screening test, and early detections (13).

One of the most common complications of GDM is macrosomic babies ( $>4 \mathrm{Kg}$. and more babies weights) (14). Our results showed the adaptation of placenta with baby weight; because low placental weight was not seen in GDM women.

One of the influencing factors on placental weight is gestational age. Gestational age is known as a principal and determinant factor of placental weight. Kinare et al. stated that the capacity of fetal weight growth is determined by placental growth (15), and between placental volume in 15 to 18 weeks gestation ages to placental weight at birth and birth weight found significantly correlation. Molteni et al. have shown the average placental weight is related to gestational age (16). Placental weight increases in infants proportionately with gestational age. While in infants with SGA were not seen any change from 36 weeks gestation (12). Pardi et al. entitled there is a significant difference between placental weight in the second trimester gestation with placental weight at birth (7); but Lo et al. have proved there is no significant difference between placental weight and gestational age (7). Our data were similar to Lo's research perhaps because more admission pregnant women in term that placental growth was the same for all of them.

We found indirect correlation between Cesarean section and placental weight; perhaps because one of Cesarean section indications is fetal distress that consists of meconium defecation. Meconium is affected on Apgar score. The result of Lao et al. study was vice versa (18). In their study, there were no significant differences in placental weight or birth weight between neonates with presence or absence of meconium stained amniotic fluid.

In other research, although low Apgar score wasn't observed in high placental weight there were no significant differences between low Apgar score and high placental weight (19). 
In different studies it has been demonstrated that male fetuses gain significantly greater weight as compared to female fetuses from $34^{\text {th }}$ to $42^{\text {nd }}$ week of gestation. Because placental weight has a relationship with infant weight, there should be a significant correlation between infant sex and placental weight $(7,19,20)$. However, we found no correlation, perhaps due to differences in ethnic and/or genetic factors. In our research the prevalence of low- and highweight placentas in fetuses under distress were $3.9 \%$ and $2.9 \%$, respectively. In addition, the ratio of women with low placental weight who had Cesarean section to women with natural vaginal delivery was 3.9/0.6. This ratio was 4.4/1.6 for high placental weight. Burkhardt et al. found mean placental weight from vaginal deliveries to be $76 \mathrm{~g}$ lighter than from Cesarean sections (21). The prevalence of low and high weight placentas from Cesarean section labors were more than from normal vaginal labors. This is corresponded with the prevalence of fetus distress, that consequently causes Apgar score decline especially in cases of low placental weight. It should be noted that we could not gather some variables such as $\mathrm{CBC}$ and hemoglobin during pregnancy; as well as body mass index in early pregnancy because most women have had prenatal cares in different health centers in other counties and villages. Godfrey et al. showed maternal hemoglobin levels influences placental weight, as if anemia and iron deficiency during pregnancy are associated with large placental weight (5).

CONCLUSION: Placenta is essential for normal fetal development and failure of the placenta can result in fetal problems. Because of growing evidence for a correlation of placental weight with chronic diseases in later life, we suggest attention and correct examination of placenta and recording all of the observations in patients' files as an important evidence for future. With evaluation and follow up of placenta growth in early pregnancy, we can prevent the risks for fetal life and improves infant health.

PREVENTION ASPECT: There is significant association between the placental weight and the neonatal outcome. Careful monitoring of the placenta should be a part of routine practice of the consultant. Placental monitoring and identification of modifiable high risk factors can improve the fetal outcome

\section{REFERENCES:}

1. Hindmarsh PC, Geary MP, Rodeck CH, Jackson MR, Kingdom JC. Effect of early maternal iron stores on placental weight and structure. Lancet. 2000 Aug 26;356(9231):719-723.

2. Heinonen S, Taipale P, Saarikoski S. Weights of placentae from small-for-gestational age infants revisited. Placenta. 2001 May; 22(5):399-404.

3. Thame M, Osmond C, Wilks RJ, Bennett FI, McFarlane-Anderson N, Forrester TE. Blood pressure is related to placental volume and birth weight. Hypertension. 2000 Feb;35(2):662-667.

4. Perry IJ, Beevers DG, Whincup PH, Bareford D. Predictors of ratio of placental weight to fetal weight in multiethnic community. BMJ. 1995 Feb 18; 310(6977): 436-439.

5. Godfrey KM, Redman CW, Barker DJ, Osmond C. The effect of maternal anaemia and iron deficiency on the ratio of fetal weight to placental weight. Br J Obstet Gynaecol. 1991 Sep;98(9):886-891.

6. Barker DJ, Bull AR, Osmond C, Simmonds SJ. Fetal and placental size and risk of hypertension in adult life. BMJ. 1990 Aug 4;301(6746):259-262. 
7. Lo YF, Jeng MJ, Lee YS, Soong WJ, Hwang B. Placental weight and birth characteristics of healthy singleton newborns. Acta Paediatr Taiwan. 2002 Jan- Feb; 43(1):21-25.

8. Little RE, Zadorozhnaja TD, Hulchiy OP, Mendel NA, Shkyryak-Nyzhnyk ZA, Chyslovska $\mathrm{N}$, Gladen BC. Placental weight and its ratio to birthweight in a Ukrainian city. Early Hum Dev. 2003 Apr;71(2):117- 127.

9. Ruangvutilert P, Titapant V, Kerdphoo V. Placental ratio and fetal growth pattern. J Med Assoc Thai. 2002 Apr; 85(4):488-495.

10. Myatt L. Role of placenta in preeclampsia. Endocrine. 2002 Oct;19(1):103-111.

11. Bortolus R, Chatenoud L, Di Cintio E, Rossi P, Benzi G, Surace M, Parazzini F. Placental ratio in pregnancies at different risk for intrauterine growth. Eur J Obstet Gynecol Reprod Biol. 1998 Oct; 80(2): 157-158.

12. Wagaarachchi PT, Fernando L, Premachadra P, Fernando DJ. Screening based on risk factors for gestational diabetes in an Asian population. J Obstet Gynaecol. 2001 Jan;21(1):32-34.

13. Brody SC, Harris R, Lohr K. Screening for gestational diabetes: a summary of the evidence for the U.S. Preventive Services Task Force. Obstet Gynecol. 2003 Feb;101(2):380-392.

14. Cunningham FC, Gant NF, Leveno KJ, Gilstrap LC, Hauth JC, Wenstrom KD. Williams Obstetric. 21st ed. Philadelphia: McGraw Hill, 2001. P. 558-559.

15. Kinare AS, Natekar AS, Chinchwadkar MC, Yajnik CS, Coyaji KJ, Fall CH, Howe DT. Low midpregnancy placental volume in rural Indian women: A cause for low birth weight? Am J Obstet Gynecol. 2000 Feb;182(2):443-448.

16. Molteni RA, Stys SJ, Battaglia FC. Relationship of fetal and placental weight in human beings: fetal/placental weight ratios at various gestational ages and birth weight distributions. J Reprod Med. 1978 Nov; 21(5):327-334.

17. Pardi G, Marconi AM, Cetin I. Pathophysiology of intrauterine growth retardation: role of the placenta. Acta Paediatr Suppl. 1997 Nov;423:170-172.

18. Lao TT, Wong WM. Implications of a high placental ratio in pregnancies with appropriate-for-gestational age neonates. Gynecol Obstet Invest. 2001;52(1):34- 37.

19. Yu KM. [Relation between placental morphometry and fetal growth]. Zhonghua Fu Chan Ke Za Zhi. 1992 Jul; 27(4):217-219. Chinese.

20. Hsieh TT, Hsu JJ, Chen CJ, Chiu TH, Liou JD, Hsieh CC, Lo LM, Kuo DM, Soong YK. Analysis of birth weight and gestational age in Taiwan. J Formos Med Assoc. 1991 Apr;90(4):382387.

21. Burkhardt T, Schäffer L, Schneider C, Zimmermann R, Kurmanavicius J. Reference values for the weight of freshly delivered term placentas and for placental weight-birth weight ratios. Eur J Obstet Gynecol Reprod Biol. 2006 Sep-Oct;128(1-2):248-252.

Table 1. Mean and standard deviation for some important variables

\begin{tabular}{|l|l|l|l|l|}
\hline Variables & Mean & Max. & Min. & SD \\
\hline Birth weight (g) & 3214.3 & 4800 & 1200 & 529.74 \\
\hline Mother age(years) & 25.35 & 45 & 15 & 5.64 \\
\hline Gestational age(days) & 274.5 & 304 & 259 & 9.56 \\
\hline Placenta weight (g) & 529.7 & 1200 & 250 & 113.52 \\
\hline Apgar score(5 min.) & 9.28 & 10 & 0 & 1.2 \\
\hline Parity (No.) & 0.66 & 6 & 0 & 0.98 \\
\hline
\end{tabular}


Table 2. Placental weights distribution

\begin{tabular}{|l|l|l|}
\hline Placental weight group & Number & Percent \\
\hline$<330$ grams & 22 & 2 \\
\hline $330-750$ grams & 1036 & 95.2 \\
\hline$>750$ grams & 30 & 2.8 \\
\hline Total & 1088 & 100 \\
\hline
\end{tabular}

.Table 3. Summary of findings analyses $(n=1088)$

\begin{tabular}{|c|c|c|c|c|c|c|}
\hline & & \multicolumn{4}{|c|}{ Placental weight Group } & \multirow[b]{2}{*}{ P value } \\
\hline & $\begin{array}{l}\text { Variable } \\
\text { categories }\end{array}$ & $\begin{array}{l}<330 \\
\mathrm{~g}\end{array}$ & $\begin{array}{l}330-750 \\
\mathrm{~g}\end{array}$ & $>750 \mathrm{~g}$ & Total & \\
\hline \multirow[t]{5}{*}{ Mothers parity } & 0 & 14 & 604 & 12 & 630 & \multirow[t]{5}{*}{$0.95>\mathrm{P}>0.90$} \\
\hline & 1 & 6 & 278 & 12 & 296 & \\
\hline & 2 & 2 & 92 & 2 & 96 & \\
\hline & $3+$ & 0 & 62 & 4 & 66 & \\
\hline & Total & 22 & 1036 & 30 & 1088 & \\
\hline \multirow[t]{6}{*}{ Mothers age groups } & $<19$ & 6 & 164 & 2 & 172 & \multirow[t]{6}{*}{$0.95>\mathrm{P}>0.90$} \\
\hline & $20-24$ & 8 & 334 & 4 & 346 & \\
\hline & $25-29$ & 4 & 280 & 12 & 296 & \\
\hline & $30-34$ & 2 & 184 & 10 & 196 & \\
\hline & $35-39+$ & 2 & 74 & 2 & 78 & \\
\hline & Total & 22 & 1036 & 30 & 1088 & \\
\hline \multirow{3}{*}{$\begin{array}{l}\text { Mothers } \\
\text { preeclampsia }\end{array}$} & Yes & 6 & 64 & 4 & 74 & \multirow[t]{3}{*}{0.0002} \\
\hline & No & 16 & 968 & 26 & 1010 & \\
\hline & Total & 22 & 1032 & 30 & 1084 & \\
\hline \multirow[t]{3}{*}{ Mothers diabetes } & Yes & 0 & 8 & 2 & 10 & \multirow[t]{3}{*}{0.00035} \\
\hline & No & 22 & 1028 & 28 & 1078 & \\
\hline & Total & 22 & 1036 & 30 & 1088 & \\
\hline \multirow{4}{*}{$\begin{array}{ll}\text { Neonates weight } \\
\text { group }\end{array}$} & $<2.5 \mathrm{~kg}$ & 16 & 76 & 0 & 92 & \multirow[t]{4}{*}{$<0.0001$} \\
\hline & $2.5-3.5 \mathrm{~kg}$ & 6 & 702 & 10 & 718 & \\
\hline & $>3.5 \mathrm{~kg}$ & 0 & 258 & 20 & 278 & \\
\hline & Total & 22 & 1036 & 30 & 1088 & \\
\hline \multirow{3}{*}{$\begin{array}{ll}\text { Apgar } & \text { score(5 } \\
\text { minutes) } & \\
\end{array}$} & $0-8$ & 8 & 66 & 2 & 76 & \multirow[t]{3}{*}{$<0.00035$} \\
\hline & 8-10 & 14 & 967 & 28 & 1009 & \\
\hline & Total & 22 & 1033 & 30 & 1085 & \\
\hline \multirow[t]{3}{*}{ Fetal distress } & Yes & 8 & 188 & 8 & 204 & \multirow[t]{3}{*}{0.05} \\
\hline & No & 14 & 848 & 22 & 884 & \\
\hline & Total & 22 & 1036 & 30 & 1088 & \\
\hline \multirow[t]{3}{*}{ Delivery route } & Vaginal & 4 & 610 & 10 & 624 & \multirow[t]{3}{*}{0.00001} \\
\hline & Caesarean section & 18 & 420 & 20 & 458 & \\
\hline & Total & 22 & 1030 & 30 & 1082 & \\
\hline
\end{tabular}

